\section{The case of the curious bill}

\author{
John R. Krebs
}

THE evolution of complex traits is a classic problem in natural selection. How can a character such as the vertebrate eye, which relies on the coordinated functioning of many separate parts, evolve by the gradual accretion of improvements? Surely, the argument goes, intermediates would be of no selective advantage because the character 'works' only if all its parts function together. The usual answer to this point, expressed forcefully and clearly by Richard Dawkins', relies on advocacy rather than direct evidence: "Without an eye you are totally blind. With half an eye you may at least be able to detect the general direction of a predator's movement . . . . And this may make all the difference between life and death". For this reason, the results reported on page 519 of this issue ${ }^{2}$ by Benkman and Lindholm are of general interest. Their experiments show how a complex and improbable trait, the crossed mandibles of the crossbill, can have a potential selective benefit that increases as the expression of the trait increases.

Crossbills have remarkable beaks: the lower mandible twists either to the right or left of, and crosses over, the upper one (see figure). According to legend, the crossbill's mandibles acquired their shape as a result of the birds trying to pull the nails from the hand of Jesus on the cross, whilst the red colour of the male was said to have arisen from the stain of Christ's blood $^{3}$. A more utilitarian, darwinian view is that the beak is an adaptation for removing seeds from conifer cones, allowing crossbills access to parts of the cone that other birds cannot reach. Newton ${ }^{+}$gives the following description of how this is done.

A bird first wrenches off a cone in its bill, carries it to some firm, horizontal branch, and clamps it between one of its feet and the perch. It then works the tip of its beak behind one of the scales, while the cone is held so that it points forwards and slightly to one side. A bird with the lower mandible deflected to the right holds the cone in its right foot and vice versa. The result is that, whether the bill crosses to the right or left, the tip of the lower mandible is always brought to bear on the cone itself and the upper one on the inside of one of the scales. The lower mandible is then moved sideways towards the body of the cone, so that the scale is raised by the tip of the upper one. The seed, once released, is scooped out by the protrusible tongue.

It is widely accepted that the shape of birds' bills reflects selection for increased feeding efficiency, and as long ago as 1944 David Lack ${ }^{5}$ pointed out that the three species of crossbill in Europe have beaks that match their preferred food (see figure). The parrot crossbill (Loxia pytyop- sittacus) has the largest and most heavily built beak and it feeds on tough cones of Pinus, the intermediate common crossbill ( $L$. curvirostra) feeds on slightly less hard cones of Picea, whilst the slender bill of the two-barred crossbill ( $L$. leucoptera) is used for feeding on the small, soft cones of Larix. Long-term studies of Darwin's finches have shown that natural selection can act to produce rapid changes in beak shape or size within a species in relation to year-to-year changes in seed hardness". Even within the lifetime of an individual, subtle, reversible, seasonal changes in beak shape and size may be related to changes in feeding niche?

In their experiment, Benkman and Lindholm used nail clippers to trim the

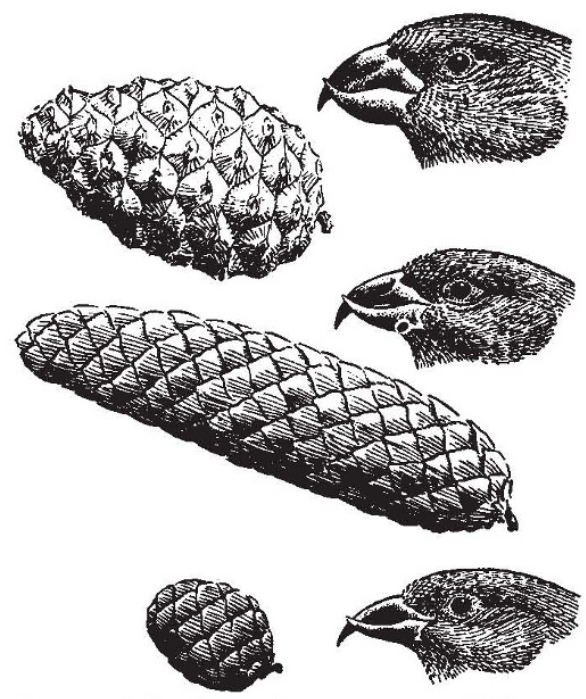

Heads of the three European crossbill species, and the main cones eaten. Top, parrot crossbill and pine cone. Centre, common crossbill and spruce cone. Bottom, two-barred crossbill and larch cone. (Reproduced from Finches by lan Newton, Collins, 1972.)

crossed ends of the bills of crossbills. This manipulation, akin to clipping toenails, causes no serious damage and, further, the crossed mandibles gradually regrow over a period of weeks. This mimics the process of growth of the young crossbill's beak. Nestlings have uncrossed bills: crossing over starts at about the age of 27 days (one week after fledging) and is compete by about 45 days, when youngsters are able to feed effectively on cones.

Benkman and Lindholm measured the efficiency with which a subspecies of common crossbill ( $L$. curvirostra minor) extracted seed from hemlock ( $T$ suga heterophylla) cones both immediately after bill docking and during the four-week period of gradual regrowth of the crossed mandibles. They found that the time taken to extract a seed from closed hemlock cones decreased gradually with increasing regrowth of the crossed mandibles. In other words, performance improved progressively with increasing expression of the trait. This was not due simply to the birds' learning to cope with trimmed bills, because the time required to extract a seed from open cones (cones open as they dry out) did not increase in the same way with regrowth of the mandibles. Nor was the effect due to a general impairment of foraging ability, illustrated by the fact that bill trimming had no effect on the time required to handle and consume a seed once it had been extracted. The birds with trimmed bills were similar in their performance to another species, the pine siskin (Carduelis pinus), which forages on open pine cones but is relatively unsuccessful at extracting seeds from closed cones.

Does this experiment provide a satisfactory demonstration that there could in principle be progressive selection for the evolution of a complex trait? The answer is only partially in the affirmative. The experiment manipulated only one aspect of the trait. As well as a crossed bill, successful extraction of seeds from closed cones requires other morphological traits such as asymmetric jaw muscles (the asymmetry has to match the "handedness' of the bill), an elongated, cartilagecontaining tongue and a flexible jaw hinge. Further, these morphological traits have to be integrated wth the appropriate motor patterns. Benkman and Lindholm show that if the crossbill has all the other features required for cone opening, it is more efficient at extracting seeds with a crossed bill. This does not answer the question of how bill, muscle, tongue and behaviour came together during evolution, nor does it indicate whether morphological evolution is driven by behaviour or the other way round.

Nevertheless the study offers a glimpse of a possible model system in which to study such questions. Bird fanciers have produced hybrids between crossbills and other finches such as the greenfinch ( $\mathrm{Car}$ duelis chloris) with less specialized bills ${ }^{+}$. Perhaps an analysis of the genetics, morphology and behaviour of these hybrids would provide an avenue along which to explore further the evolution of a complex trait.

John R. Krebs is in the Edward Grey Institute of Field Ornithology, Department of Zoology, University of Oxford. South Parks Road, Oxford OX1 3PS, UK.

\footnotetext{
1. Dawkins, R. The Blind Watchmaker (Longman, London, 1986)

2. Benkman, C.W. \& Lindholm, A.K. Nature 349, 519-520 (1991)

3. Nethersole-Thompson, D. Pine Crossbills (T. \& A.D. Poyser, Berkhamsted, 1975).

Newton, I. Finches (Collins, London, 1972).

5. Lack, D. Ibis 86, 552-553 (1944).

6. Gack, D. I. B. Ecology and Evolution of Danwin's Finches (Princeton, Univ. Press, 1986).
}

7. Gosler, A.G. Ibis 129, 451-476 (1987). 